\title{
Journal Club: Risk of new-onset epilepsy and refractory epilepsy in older adult stroke survivors
}

Robert Hurford, MSc, and Linxin Li, DPhil

Neurology ${ }^{\circledR}$ 2020;94:758-760. doi:10.1212/WNL.0000000000008942

Correspondence

Dr. Li

linxin.li@ndcn.ox.ac.uk

The incidence of stroke increases with age and stroke is a significant cause of new-onset epilepsy in the elderly. ${ }^{1} \mathrm{~A}$ few small studies previously suggested that older patients with epilepsy and those with poststroke epilepsy tend to respond to antiepileptic drug (AED) treatment and are less likely to become refractory, ${ }^{2,3}$ but this relationship is underinvestigated.

In this Journal Club article, Burneo et al. ${ }^{4}$ conducted a large cohort study in Ontario, Canada, confirming this relationship. Moreover, they showed that most of the deaths in those with poststroke epilepsy were unrelated to stroke or epilepsy.

\section{Hypothesis and design}

Given the lack of studies of adequate design (i.e., many were case-control studies) or sufficient size, the authors' main aim was to more reliably determine the incidence and factors associated with poststroke epilepsy at older ages and its long-term prognosis. Although not expressly stated, the implied hypothesis was that age is protective of poststroke epilepsy and refractory poststroke epilepsy, in accordance with previous studies.

This has important implications for health care service planning (for example, to facilitate appropriate investigation and clinical care of these patients) and patient counseling with regards to future risk of epilepsy and addresses interesting pathophysiologic questions.

The study was a large retrospective cohort study using multiple linked administrative datasets from the universal health care system in Ontario, Canada.

\section{Methods}

\section{Case identification}

The authors used the Ontario Stroke Registry to identify patients with stroke discharged from 1 of 12 stroke centers for the first event between 2003 and 2009. An initial cohort of 42,172 patients was identified. Stroke subtypes included hemorrhagic, ischemic, or other (including TIAs and unspecified).

The largest exclusion criterion was a missing or invalid health card number. Study-specific exclusions included those younger than 67 years, with acute symptomatic seizures or death prior to discharge, seizures in the preceding 10 years (determined by validated ICD-9/10 codes), AED use in the preceding 2 years, or brain tumor/epilepsy surgery.

\section{Outcome identification}

Patients were followed administratively for 2 years after discharge to assess for poststroke epilepsy. A predefined algorithm identified cases hospitalized for epilepsy or connected to $\geq 3$ physician billings for seizures/epilepsy 30 days apart. Refractory epilepsy was operationally defined as not responding to 2 AED intervention trials within 18 months. 
MRI brain and EEG was considered adequate investigation for seizures, in line with published standards for investigation of new-onset seizures.

A state mortality registry was used to determine the 5-year case-fatality for those with poststroke epilepsy. Relevant ICD-9 codes were used to identify cause-specific deaths, which included stroke-related, epilepsy-related, and allcause.

\section{Factors associated with poststroke epilepsy}

Covariates used in the model were chosen from the literature as those previously shown to affect long-term outcomes following stroke due to the small number of patients identified with refractory poststroke epilepsy. These included stroke type, age, sex, thrombolysis receipt, anticoagulant medication receipt, and stroke severity.

Different datasets of Ontario's universal health care system were linked with the main dataset to identify the above covariates of interest (see reference 4 for details).

\section{Statistical analysis}

Simple statistics were used to assess for baseline differences in those with and without poststroke epilepsy. Missing data were accounted for by multiple imputation prior to multivariable analysis.

The risk of developing poststroke epilepsy and refractory poststroke epilepsy was calculated using 2 Fine and Gray competing risk regression models (accounting for the risk of death).

Multivariable analysis including predefined covariates was performed to assess the factors associated with poststroke epilepsy and refractory epilepsy.

\section{Results}

From the initial cohort, 23,034 patients (54.6\%) were excluded, creating a final study population of 19,138 . Of these, 210 (1.1\%) developed epilepsy within 2 years; 24 (11.4\%) were assessed with EEG and 19 (9.0\%) with MRI brain. During an average follow-up of 3.9 years, 27 (12.9\%) cases of poststroke epilepsy became refractory.

Poststroke epilepsy was associated several variables, including younger age, higher Charlson Comorbidity Index, and a greater prevalence of depression, but only younger age and acute treatment with thrombolysis were independent predictors in the prespecified multivariate model. By contrast, predictors for refractory poststroke epilepsy included younger age and female sex. Interestingly, the initially significant independent effects of anticoagulation and high Canadian Neurologic Scale score both diminished over the course of follow-up.
The 210 patients with poststroke epilepsy had an all-cause 5year mortality rate of $46.2 \%$, and $13(6.2 \%)$ died of strokerelated causes. No patient died of epilepsy-related causes.

\section{Interpretation}

This study by Burneo et al. ${ }^{4}$ has contributed to the literature by reinforcing previously suggested trends of age-related protection from poststroke epilepsy. The strengths include its large, clearly defined population and use of validated registrybased methods to capture multiple covariates and mortality.

The main limitation, common to many registry-based studies, pertains to potential biases with incomplete capture of all cases and outcomes resulting in possible underestimation of the incidence of poststroke epilepsy at older ages.

\section{Case ascertainment}

Case selection bias might contribute to underascertainment of patients with high risk of poststroke epilepsy.

First, although the study has a clearly defined population, in a strict epidemiologic sense it is a multicenter hospital-based study. Ideal population-based studies use multiple overlapping methods of case ascertainment to identify patients from primary and secondary care records to capture those with out-of-area or inpatient strokes, who may be some of the frailest patients with a high risk of poststroke epilepsy. ${ }^{5}$

Second, more than half the initial cohort was excluded, including 3,573 patients with missing or invalid health card numbers. These are likely to include those with low socioeconomic status and a plausibly higher risk of poststroke epilepsy. ${ }^{6,7}$

Third, patients with prior AED use were excluded from the study as a surrogate marker of preexisting epilepsy. However, the coding would not have distinguished patients prescribed AEDs for alternative diagnoses, such as severe depression or neuropathic pain. Exclusion of these patients could also result in underestimation of poststroke epilepsy risk, given the known associations of depression and epilepsy, ${ }^{6}$ similarly demonstrated in this study.

Finally, patients with seizures prior to discharge were excluded, but it is known that there are 2 peaks in poststroke seizure/epilepsy occurrence: on the first day and 6-12 months after a stroke. ${ }^{7,8}$

In addition to potential selection bias, lack of information or information bias in relation to the stroke subtypes can also limit the interpretation of the study results.

For example, all subtypes of stroke and TIA were included, but no sensitivity analyses were performed, despite the higher risk of poststroke epilepsy in those with intracerebral hemorrhage. ${ }^{8,9}$ Whether the identified trends are driven by one subtype in particular is not known as the proportional 
representation of different stroke subtypes, including those unable to be determined, is not reported.

\section{Outcome ascertainment}

Underascertainment of the outcome would also influence the apparent low risk of poststroke epilepsy at older ages.

The authors identified cases of poststroke epilepsy using a previously validated algorithm, but with a sensitivity of only $73.7 \%$. Reasons for this, and whether there could be any systematic bias, are not explored in the article but one might argue that increasing age is likely to be associated with falsenegative cases; for example, minor seizures could be easily missed or ignored in those living in nursing homes. Other possible explanations for the low sensitivity include noncomprehensive codes and out-of-area events.

\section{Predictors}

The authors have provided some explanations as to their remarkable finding that age appears protective for poststroke epilepsy. However, alternative explanations include the potential biases we have outlined leading to lower outcome ascertainment.

Moreover, in the multivariate model, the authors have not explained how the covariates interaction between anticoagulant medication receipt and time and stroke severity and time were chosen; it seems likely this was a data-driven post hoc analysis.

\section{Long-term mortality}

The authors found a very low risk of stroke-related death and no patients died of epilepsy-related causes. However, it is unknown whether all relevant ICD mortality codes were used, for example, capturing cases of sudden unexpected death in epilepsy, which could be coded as sudden cardiac death. Yet there is unlikely to be any systematic bias here since it is plausible there is an increased chance of deaths being attributed to stroke or epilepsy with a relevant history, but the authors in fact found the opposite trend.

\section{Investigations proposed for poststroke epilepsy}

The authors' standard of investigation of poststroke epilepsy was based on general guidelines for new-onset seizures and, unsurprisingly, they report low compliance in this cohort. In our experience, EEG in particular is unlikely to be management-changing in this context and the authors have not provided any commentary on why they believe this a clinically relevant workup for an elderly patient with poststroke epilepsy.

Despite the large study population, given the lack of granularity in stroke subtyping and the exclusion of large numbers of patients with potential for systematic bias, the results would be difficult to translate to clinical practice. Similarly, the authors highlight an underinvestigation of poststroke epilepsy cases, but do not make the case that their standard is clinically meaningful.

Nevertheless, the study has made an important contribution to the field and highlighted important trends that should be explored in future prospective studies.

\section{Author contributions}

R. Hurford: drafting/revising the manuscript, study concept or design, accepts responsibility for conduct of research and final approval. L. Li: drafting/revising the manuscript, analysis or interpretation of data, accepts responsibility for conduct of research and final approval.

\section{Study funding}

No targeted funding reported.

\section{Disclosure}

The authors report no disclosures relevant to the manuscript. Go to Neurology.org/N for full disclosures.

\section{References}

1. Hauser WA, Annegers JF, Kurland LT. Incidence of epilepsy and unprovoked seizures in Rochester, Minnesota: 1935-1984. Epilepsia 1993;34:453-468.

2. Huang YN, Gao S, Li SW, et al. Vascular lesions in Chinese patients with transient ischemic attacks. Neurology 1997;48:524-525.

3. Hernandez-Ronquillo L, Adams S, Ballendine S, Tellez-Zenteno JF. Epilepsy in an elderly population: classification, etiology and drug resistance. Epilepsy Res 2018;140: 90-94.

4. Burneo JG, Antaya TC, Allen BN, Belisle A, Shariff SZ, Saposnik G. The risk of newonset epilepsy and refractory epilepsy in older adult stroke survivors. Neurology Epub 2019 July 10

5. Feigin V, Hoorn SV. How to study stroke incidence. Lancet 2004;363:1920.

6. Li X, Sundquist J, Sundquist K. Socioeconomic and occupational risk factors for epilepsy: a nationwide epidemiological study in Sweden. Seizure2008;17:254-260.

7. Hesdorffer DC, Tian H, Anand K, et al. Socioeconomic status is a risk factor for epilepsy in Icelandic adults but not in children. Epilepsia2005;46:1297-1303.

8. So EL, Annegers JF, Hauser WA, O'Brien PC, Whisnant JP. Population-based study of seizure disorders after cerebral infarction. Neurology1996;46:350-355.

9. Bladin CF, Alexandrov AV, Bellavance A, et al. Seizures after stroke: a prospective multicenter study. Arch Neurol2000;57:1617-1622. 


\section{Neurology}

\section{Journal Club: Risk of new-onset epilepsy and refractory epilepsy in older adult stroke survivors}

Robert Hurford and Linxin Li

Neurology 2020;94;758-760 Published Online before print January 28, 2020

DOI 10.1212/WNL.0000000000008942

This information is current as of January 28,2020

\section{Updated Information \&} Services

References

Subspecialty Collections

Permissions \& Licensing

Reprints including high resolution figures, can be found at: http://n.neurology.org/content/94/17/758.full

This article cites 8 articles, 2 of which you can access for free at: http://n.neurology.org/content/94/17/758.full\#ref-list-1

This article, along with others on similar topics, appears in the following collection(s):

All Cerebrovascular disease/Stroke

http://n.neurology.org/cgi/collection/all_cerebrovascular_disease_strok e

\section{All Epilepsy/Seizures}

http://n.neurology.org/cgi/collection/all_epilepsy_seizures

CME

http://n.neurology.org/cgi/collection/cme

Cohort studies

http://n.neurology.org/cgi/collection/cohort_studies

Information about reproducing this article in parts (figures,tables) or in its entirety can be found online at:

http://www.neurology.org/about/about_the_journal\#permissions

Information about ordering reprints can be found online:

http://n.neurology.org/subscribers/advertise

Neurology ${ }^{\circledR}$ is the official journal of the American Academy of Neurology. Published continuously since 1951, it is now a weekly with 48 issues per year. Copyright @ 2020 American Academy of Neurology. All rights reserved. Print ISSN: 0028-3878. Online ISSN: 1526-632X.

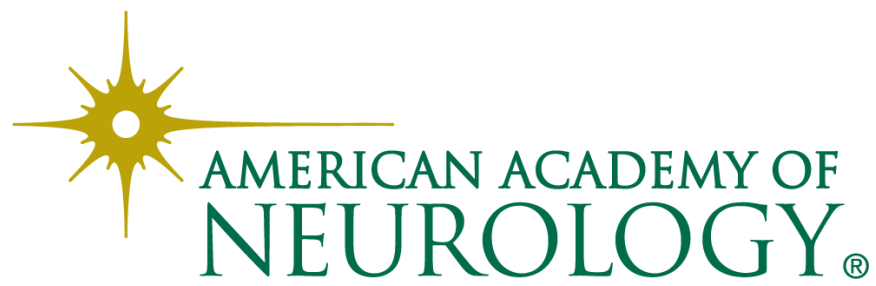

